\title{
MJN \\ STRESS LEVEL AMONG NURSING STUDENTS IN HAWLER MEDICAL UNIVERSITY AT ERBIL CITY- IRAQ
}

\section{Mosleh Saber Kareem}

\author{
Psychiatric Nursing, College of Nursing, Hawler Medical University, Erbil, Iraq
}

Corresponding Author's Email: mosleh.saber@yahoo.com

\begin{abstract}
Background and Objective: Stress is a general term describing the psychological and physical response to a stimulus that alters the body's equilibrium. Nowadays, there is increasing pressure and stress in students, this might be related to studies, examination, peer, teachers or parent's pressure. Aims of this study were to assess the severity of stress among college students and association between socio-demographic. Methods: A crosssectional study was conducted on 200 student nurses of all stages and both genders in College of Nursing at Hawler Medical University/Erbil City of Kurdistan Region-Iraq. Data were collected from students through interviews based on a designed questionnaire. In order to analyse the results of the study data were entered in SPSS (version 23) frequency, percentage and Chi-square tests were used for interpretation of data. Results: The mean age $( \pm \mathrm{SD})$ was $21.06( \pm 2.58)$ years. Most $(68.5 \%)$ of them were female $(85 \%)$ single and $(63.5 \%)$ with standard economic status. About $39.5 \%$ of the study sample lived in the urban area, the highest percentage (98\%) were Muslim, and (97.5\%) were Kurdish. While most $(65 \%)$ of them suffered from moderate stress level and only $13 \%$ were with high stress level. There was no significant association between the level of stress and their socio-demographic characteristics, only gender was significant statistically $(P$ Value $=0.029$ ). Conclusion: The study concluded that most of nursing students have stress symptoms.
\end{abstract}

Keywords: Stress, Students, Assessment, College, University

\section{INTRODUCTION}

Stress is a general term describing the psychological and physical response to a stimulus that alters the body's equilibrium (Kosslyn \& Rosenberg, 2006). Nowadays, there is increasing pressure and stress among students. This might be related to studies, examination, peer, teachers or parent's pressure (Behere, Yadav \& Behere, 2011). Nursing students, to some extent, experienced stress in clinical learning environment.The most common stressors were related to clinical and educational dimensions. Several studies suggested that teaching and learning modalities and the workload of nursing students must be reviewed (Liu et al., 2015).

The study by Mahfouz \& Alsahli, (2016) on nursing student's revealed that out of 51 nursing students 48 (94.1\%) had high stress whereas $3(5.9 \%)$ had moderate stress, while there is no student with low stress. The outcomes of this study indicated that the nursing students are mainly facing the academic stress as there was positivity among the students in the clinical settings and environmental stressors also have great impact on student's learning (Parveen \& Inayat, 2017). It could be inferred from this investigation that Filipino student nurses, especially junior students were exposed to different stressors during their nursing education and training, however, their physio-psychosocial health in general was good.

Results clearly show that stress may have an impact on the physio-psycho-social health of the students. This is strengthened by Lazarus \& Folkman, (1984) whose theory describes that stress could have effects on people's health and wellbeing. The results provided crucial and valuable information for nurse educators in recognizing students' needs, enabling their learning both in the academic and clinical setting, and planning 
operative interventions and plans to decrease or prevent stress in nursing education and training (Labrague, 2013). Transition of students from school environment to university environment could cause a psychological, academic and social shock, since the two educational systems has huge differences. The student in university face new methods of teaching, new academic requirements, new type of relations between students and faculties and even new relations among students themselves.

Stress is one of the main aspects of our modern life, resulted from the rapid changes around. So, this age is called the age of stress. As a result, students suffer from academic stress resulted from testing, home works and other school requirements which may exceed their abilities. Mothers have their own stress resulted from child education, employees, leaders, and all community have different types of stress, sometimes the same person suffers from different types of stress at the same time (Thawabieh \& Qaisy, 2012). There is more to our physical health than germs and disease; we also need to consider the amount of stress in our lives and how we deal with that stress.

Initial research in this area documented some extreme cases in which people's health is influenced by stress (Aroson, Wilson \& Akert, 2007). Stress is one of the serious issues that affect university student's life; its effects could be reflected in student social, academicals, and mental health. Stress can lead to academic decline, poor relationships with peers and family members and overall dissatisfaction with life. So each university must assess its students stress in order to provide them with the suitable mental health care and the efficient methods to cope with stress (Stoppler, 2016). The use of the term stress is now so integrated into our thoughts that it sometimes feels it has always been there. In fact stress, as we currently think of it, is a relatively new concept and is one that continues to evolve. Had we lived in the fourteenth century we would most certainly have used the term stress. But, with one or two notable exceptions, it would have had very little to do with our psychological state, except perhaps by implication. Stress had more to do with adversity, hardship or some form of affliction. It was not until the eighteenth and nineteenth century that a shift in meaning started to occur. Nearly everyone will recognize these as expressions commonly used within medicine and psychology. Still others, like 'snapping' or 'breaking point', tend not to be used within the professions these days but they retain a position in everyday language relating to emotions or behavior (Jerry, 2016)

\section{The importance of the study}

Stress is one of the serious issues that affect university student's life; its effects could be reflected in student social, academicals, and mental health (Thawabieh \& Qaisy, 2012). Found that stress can lead to academic decline, poor relationships with peers and family members and overall dissatisfaction with life. So, each university must assess its students stress in order to provide them with the suitable mental health care and the efficient methods to cope with stress.

\section{METHODOLOGY}

This cross-sectional study was conducted between April $23^{\text {rd }}, 2018$ and July $21^{\text {st }}, 2018$ on 200 (50 students from each academic year) students from College of Nursing at Hawler Medical University/ Erbil City of Kurdistan Region-Iraq. A non-probability purposive sample was selected.

The sample was selected according to the following inclusion criteria: students in College of Nursing, with no psychiatric diagnosis and psychological problems, students should answer verbally, students of both genders. Exclusion criteria: Not verbal and anybody refusing participation, sick students, other students. Data were collected by same researcher using interview technique by Kurdish language, each patients interview lasted 20 minutes, the questionnaire comprised of two parts, Part I: Socio-demographic characteristics including age, gender, marital status, economic status, residence, nationality and religion and Part II: perceived stress scale, this scale is used to measure the severity of stress among students at college of nursing. Measuring of stress score using Perceived Stress Scale (PSS) which includes 10 questions and each question has 5 responses that are marked from 0 to 4 and the student have to select one response that are more suitable with his emotional state. Individual scores on the PSS can range from 0 to 40 with higher scores indicating higher perceived stress, selects one response that is more suitable with his or her emotional state. It also observes stress level as the following: 0-13 would be considered low stress, 14-26 would be considered moderate stress and 27-40 would be considered high perceived stress (Mahfouz \& Alsahli, 
2016). The ethical approvals for conducting this study was obtained from ethical committee in College of Nursing/ Hawler Medical University. Data were analyzed using the Statistical Package of Social Sciences (SPSS, Version 22) performed using descriptive statistical data analysis approach; such as frequencies, percentages, and inferential statistical data analysis approach which is presented as Chi-Square test, all statistical procedures were tested on a probability of $p$ value based on as follows:

$\leq 0.01$ highly significant

$\leq 0.05$ significant

$>0.05$ non- significant (Mahfouz \& Alsahli, 2016)

\section{RESULTS}

Table 1: Socio-demographic characteristics of students

\begin{tabular}{|c|c|c|c|}
\hline 1 & Stage & No. & $\%$ \\
\hline & First & 50 & 25 \\
\hline & Second & 50 & 25 \\
\hline & Third & 50 & 25 \\
\hline & Fourth & 50 & 25 \\
\hline & Total & 200 & 100 \\
\hline 2 & Age & & \\
\hline & $18-22$ & 162 & 81 \\
\hline & $23-27$ & 30 & 15 \\
\hline & $28-32$ & 8 & 4 \\
\hline & Total & 200 & 100 \\
\hline 3 & Gender & & \\
\hline & Male & 63 & 31.5 \\
\hline & Female & 137 & 68.5 \\
\hline & Total & 200 & 100 \\
\hline 4 & Marital state & & \\
\hline & Single & 170 & 85 \\
\hline & Married & 30 & 15 \\
\hline & Total & 200 & 100 \\
\hline
\end{tabular}

\begin{tabular}{|c|c|c|c|}
\hline \multirow[t]{5}{*}{5} & \multicolumn{3}{|l|}{ Economic state } \\
\hline & Moderate & 66 & 33 \\
\hline & $\begin{array}{l}\text { By some means } \\
\text { (enough) }\end{array}$ & 127 & 63.5 \\
\hline & Insufficient & 7 & 3.5 \\
\hline & Total & 200 & 100 \\
\hline \multirow[t]{4}{*}{6} & \multicolumn{3}{|l|}{ Residency } \\
\hline & Urban & 79 & 39.5 \\
\hline & Suburban & 48 & 24 \\
\hline & Hostel & 73 & 36.5 \\
\hline \multirow[t]{3}{*}{7} & \multicolumn{3}{|l|}{ Religion } \\
\hline & Muslim & 196 & 98 \\
\hline & Eazidian & 4 & 2 \\
\hline \multirow[t]{4}{*}{8} & \multicolumn{3}{|l|}{ National } \\
\hline & Kurdish & 195 & 97.5 \\
\hline & Arabic & 3 & 1.5 \\
\hline & Turcoman & 2 & 1 \\
\hline
\end{tabular}

Table 1 show that $81 \%$ of participants were in the age group $81-22$ years old. The mean age $\pm \mathrm{SD}$ of the participants were $21.06 \pm 2.58$. regarding gender most $(68.5 \%)$ of the studied sample were female, The highest percentage $(85 \%)$ of the study sample was single, majority $(63.5 \%)$ of the studied samples had a somehow sufficient economic status, regarding the residential area most $(39.5 \%)$ of the study sample was in urban area, the highest percentage (98\%) were Muslim, only $2 \%$ of them were Eazidian and highest percentage (97.5\%) were Kurdish.

Table 2: Levels of Stress among 200 students

\begin{tabular}{|l|l|l|}
\hline Levels of Stress & No. & \% \\
\hline Low stress & 44 & 22.0 \\
\hline Moderate stress & 130 & 65.0 \\
\hline High stress & 26 & 13.0 \\
\hline Total & $\mathbf{2 0 0}$ & $\mathbf{1 0 0 . 0}$ \\
\hline
\end{tabular}

Table 2 shows the occurrence of severity levels of stress among students as estimated that, $22 \%$ were low stress level, while most (65\%) of them suffered from moderate stress level and only $13 \%$ of students were high stress level. 
Table 3: Association between socio-demographic characteristics of students and levels of Stress (N=200)

\begin{tabular}{|c|c|c|c|c|c|c|c|c|c|}
\hline \multirow[b]{2}{*}{ Socio-demographic } & \multirow[t]{2}{*}{ Levels of stress } & \multicolumn{2}{|c|}{ Low stress } & \multicolumn{2}{|c|}{ Moderate stress } & \multicolumn{2}{|c|}{ High stress } & \multirow[t]{2}{*}{ Total } & \multirow{2}{*}{$P$-value } \\
\hline & & No. & $\%$ & No. & $\%$ & No. & $\%$ & & \\
\hline \multirow{4}{*}{ Age group } & $18-22$ & 37 & 18.5 & 108 & 54 & 17 & 8.5 & 162 & \multirow{4}{*}{0.202} \\
\hline & $23-27$ & 5 & 2.5 & 17 & 8.5 & 8 & 4 & 30 & \\
\hline & $28-32$ & 2 & 1 & 5 & 2.5 & 1 & 0.5 & 8 & \\
\hline & Total & 44 & 22 & 130 & 65 & 26 & 13 & 200 & \\
\hline \multirow{3}{*}{ Gender } & Male & 21 & 10.5 & 36 & 18 & 6 & 3 & 63 & \multirow{3}{*}{0.029} \\
\hline & Female & 23 & 11.5 & 94 & 47 & 20 & 10 & 137 & \\
\hline & Total & 44 & 22 & 130 & 65 & 26 & 13 & 200 & \\
\hline \multirow{3}{*}{ Marital Status } & Single & 38 & 19 & 108 & 54 & 24 & 12 & 170 & \multirow{3}{*}{0.465} \\
\hline & Married & 6 & 3 & 22 & 11 & 2 & 1 & 30 & \\
\hline & Total & 44 & 22 & 130 & 65 & 26 & 13 & 200 & \\
\hline \multirow{4}{*}{ Economic Status } & Sufficient & 12 & 6 & 47 & 19 & 7 & 3.5 & 66 & \multirow{4}{*}{0.51} \\
\hline & Somehow sufficient & 29 & 14.5 & 80 & 40 & 18 & 9 & 127 & \\
\hline & Insufficient & 3 & 1.5 & 3 & 1.5 & 1 & 0.5 & 7 & \\
\hline & Total & 44 & 22 & 130 & 65 & 26 & 13 & 200 & \\
\hline \multirow{3}{*}{ Residency area } & Urban & 21 & 10.5 & 50 & 25 & 8 & 4 & 79 & \multirow{4}{*}{0.469} \\
\hline & Suburban & 10 & 5 & 33 & 16.5 & 5 & 2.5 & 48 & \\
\hline & Dormitory & 13 & 6.5 & 47 & 23.5 & 13 & 6.5 & 73 & \\
\hline \multirow{4}{*}{ Religion } & Total & 33 & 16.5 & 130 & 65 & 26 & 13 & 200 & \\
\hline & Muslim & 44 & 22 & 126 & 63 & 26 & 13 & 196 & \multirow{3}{*}{0.333} \\
\hline & Eazidian & 0 & 0 & 4 & 0 & 0 & 0 & 4 & \\
\hline & Total & 44 & 22 & 230 & 65 & 26 & 13 & 200 & \\
\hline \multirow{4}{*}{ Nationality } & Kurdish & 42 & 21 & 127 & 63.5 & 26 & 13 & 195 & \multirow{4}{*}{0.617} \\
\hline & Turkoman & 2 & 1 & 2 & 1 & 0 & 0 & 4 & \\
\hline & Arab & 0 & 0 & 1 & 0.5 & 0 & 0 & 1 & \\
\hline & Total & 44 & 22 & 130 & 65 & 26 & 13 & 200 & \\
\hline
\end{tabular}


Table 3 demonstrates the association between the socio-demographic characteristics of students and levels of stress. In general, there was no significant association between the level of stress and their sociodemographic characteristics, only with respect to gender was significant statistically $(P$-Value $=0.029)$.

Table 4: Association between Study Level of students and their levels of Stress $(N=200)$

\begin{tabular}{|c|c|c|c|c|c|c|c|c|c|}
\hline \multirow{2}{*}{\multicolumn{2}{|c|}{ Levels of Stress }} & \multicolumn{2}{|c|}{ Low stress } & \multicolumn{2}{|c|}{ Moderate stress } & \multicolumn{2}{|c|}{ High stress } & \multirow[t]{2}{*}{ Total } & \multirow{2}{*}{$P$-value } \\
\hline & & No. & $\%$ & No. & $\%$ & No. & $\%$ & & \\
\hline \multirow{5}{*}{ Study Level } & First Stage & 16 & 8 & 29 & 14.5 & 5 & 2.5 & 50 & \multirow{5}{*}{0.461} \\
\hline & Second Stage & 9 & 4.5 & 34 & 17 & 7 & 3.5 & 50 & \\
\hline & Third Stage & 11 & 5.5 & 34 & 17 & 5 & 2.5 & 50 & \\
\hline & Fourth Stage & 8 & 4 & 33 & 16.5 & 9 & 4.5 & 50 & \\
\hline & Total & 44 & 22 & 130 & 65 & 26 & 13 & 200 & \\
\hline
\end{tabular}

Table 4 shows that there were no statistically significant differences between stages of student's study and levels with stress.

\section{DISCUSSION}

Stress is also an important thing that is present in our life. But prevalence of stress for a prolonged time is not good for our health. A suitable level of stress is essential in maintaining physical and mental health as well as making positive academic achievements. Nursing students are loaded with a remarkable amount of information. They have a limited amount of time to control all the information studied. The overload of information creates a feeling of disappointment because of their inability to handle all the information at once. Therefore this may affect their performance during the examination period16. The findings of present study indicate that majority of the studied sample were in the age group 18-22 years old, this result was compatible with the results of a study conducted in college of nursing at Egypt, done by Mahfouz \& Alsahli, (2016) the results illustrates that $49 \%$ from the total of the nursing students are 21 years old consisting of the majority of the study sample (Mahfouz \& Alsahli, 2016; Parveen \& Inayat, 2017; Sayiner, 2006; Madebo, Yosef \& Tesfaye, 2016). The highest percentage of the sample was single, the result was similar to the research that was carried out in (Parveen \& Inayat, 2017; Madebo, Yosef \& Tesfaye, 2016). Regarding gender, majority of the students were female which in consistency with the study that done in Istanbul-Turkey (Sayiner, 2006; Al-Dubai et al., 2011). The current study reported that highest percentage of the study sample was Muslim with moderate economic status. This in support with the study done in Malaysia supported our study (Sayiner, 2006; Al-Dubai et al., 2011).

Results of the present study showed that the occurrence of severity levels of stress was in moderate level among the majority of student nurses. The results were similar to the results of a study conducted in Jordan by Thawabieh \& Qaisy (2012), as reported that results indicate that the students experienced a moderate level of stress (Sayiner, 2006; Madebo, Yosef \& Tesfaye, 2016). This could be either due to the different questionnaire used in other studies or it could be a real difference. Likewise, medium level of stress in the current study may be because it was done during of mid-term year examination. But from the study it was found that student during examination, faced a lot of stress that may be affect their performance. The results indicate that female students had more stress than males; this could be explained by the fact that females are subjected more to the community pressure and they are still under the pressure of the cultural habits (Thawabieh \& Qaisy, 2012; Madebo, Yosef \& Tesfaye, 2016).

The results of the present study indicated that there was significant association between the level of stress 
and the gender though there was no statistically significant association with other socio-demographic characteristics. These results were similar with the study conducted in Ethiopia that reported that there were no significant relationships between stress level and socio-demographic characteristics of student nurses was not significant statistically (only gender was statistically significant) Madebo, Yosef \& Tesfaye (2016). The current study indicated that there was no significant association between the level of stress of student nurses and their stages of study with other socio-demographic characteristics except gender. These results were similar with the study conducted in Babylon University by Emad et al., (2017) in Iraq, that shows that there were no significant associations of stress level with participant gender, study level and residence (by Emad et al., 2017). However, on the other hand study's results disagreed with present results just in gender of students, may be due to difference in questionnaire tool, sample size, culture was varied with our study, ethnicity and economic status.

\section{CONCLUSION}

The study concluded that most of the student nurses had a moderate stress. There was no significant association between student's socio-demographic characteristics and stress level except gender of the student was significant statistically. It is recommended to improve the psychological and emotional status for student nurses of all stages, especially by teaching staff along with psycho-education. Coordination between students and psychiatry hospitals to give treatment must be made to reduce stress level. Early detection of the signs and symptoms of stress by teachers is necessary in order to prevent worsening of the stress level. Conducting similar studies at the national level on a larger sample to assess stress among university students will help to cope stress among nursing student in future.

\section{REFERENCES}

Al-Dubai, S.A., Al-Naggar, R.A., Alshagga, M.A. \& Rampal, K.G. (2011). Stress and coping strategies of students in a medical faculty in Malaysia. The Malaysian Journal of Medical Sciences, 18(3), pp 57-64.

Aroson, E., Wilson, T. \& Akert, R. (2007). Social Psychology. $6^{\text {th }}$ edition. Upper Saddle River, NJ: Pearson.

Behere, S.P., Yadav, R. \& Behere, P.B. (2011). A Comparative Study of Stress Among Students of Medicine, Engineering, and Nursing. Indian Journal of Psychological Medicine, 33(2), pp 145-148.

Emad, A., Farhood, H.F., Fadhil, S.F., Kadhem, A., Ali, A.M. \& Najah, A. (2017). Assessments of Self-Esteem and Stress among Babylon Medical College students. Kerbala Journal of Medicine, 10(2), pp 2747-2755.

Jerry, K. (2016). Historical background of stress. Healthcentral. Available at: https://www. healthcentral.com /article/a-brief-history-of-the-term-stress

Kosslyn, M.S. \& Rosenberg, R.S. (2006). Psychology in context. $3^{\text {rd }}$ edition. USA: Pearson.

Labrague, L.J. (2013). Stress, Stressors, and Stress Responses of Student Nurses in a Government Nursing School. Health Science Journa1, 7(4), pp 424-435.

Lazarus, R.S. \& Folkman, S. (1984). Stress, appraisal, and coping. USA : Springer Publishing Company.

Liu, M., Gu, K., Wong, T.K.S., Luo, M.Z. \& Chan, M.Y. (2015). Perceived stress among Macao nursing students in the clinical learning environment. International Journal of Nursing Sciences, 2(2), pp 128-133.

Madebo, W.E., Yosef, T.T. \& Tesfaye, M.S. (2016). Assessment of Perceived Stress Level and Associated Factors among Health Science Students at Debre Birehane University, North Shoa Zone of Amhara Region, Ethiopia. Health Care: Current Reviews, 4(2): 166.

Mahfouz, R. \& Alsahli, H. (2016). Perceived Stress and Coping Strategies Among Newly Nurse Students in Clinical Practice. Journal of Education and Practice, 7(23), pp 118-128. 
Parveen, A. \& Inayat, S. (2017). Evaluation of factors of stress among Nursing Students. Parveen and Inayat. Advanced practice Nurse, 2:136.

Sayiner, B. (2006). Stress Level of University Students. Istanbul Ticaret University. Volume10 /2, pp 23-34. Retrived from: https://core.ac.uk/download/pdf/53031896.pdf

Stoppler, M.C. (2016). Stress. MedicineNet. Retrived from: https:/www.medicinenet.com/stress/article.htm\# stress_facts

Thawabieh A.M. \& Qaisy L.M. (2012). Assessing Stress among University Students. American International Journal of Contemporary Research, 2(2), pp 110-116. 